\title{
Herlyn-Werner-Wunderlich syndrome: a rare cause of acute urinary retention in an adolescent girl
}

\author{
Sandeep Kumar, ${ }^{1}$ K V Rajagopal, ${ }^{2}$ Lakshmikanth Halegubbi Karegowda, ${ }^{2}$ \\ Ravikanti Krishna Chaitanya ${ }^{1}$
}

'Department of

Radiodiagnosis, Kasturba Medical College, Manipal University, Manipal, Karnataka, India

${ }^{2}$ Department of Radiology, Kasturba Medical College, Manipal, Karnataka, India

\section{Correspondence to}

Professor K V Rajagopal rajagopalkv@yahoo.com

Accepted 17 March 2015

\section{DESCRIPTION}

A 14-year-old girl presented to emergency triage with acute retention of urine. There was history of cyclic pelvic pain for the past 6 months, for which she had been prescribed non-steroidal antiinflammatory drugs by a private practitioner. There was no history of ureteric colic or burning during micturition. Gynaecological history indicated menarche at 12 years followed by regular menses. There was no history of abnormal vaginal bleeding. Ultrasound of the abdomen revealed findings suggestive of bicornuate uterus with haematocolpos. Subsequently, MRI was requisitioned, revealing two widely divergent, symmetrical uterine corpii, partially fused at the cervix without any communication between their endometrial cavities (figure 1A). There was a thick hypointense left hemivaginal septum with a large ipsilateral haematocolpos appearing hyperintense on T1-weighted and hypointense on T2-weighted images, findings consistent with intracellular methaemoglobin stage of bleed. A similar intensity dilated tortuous

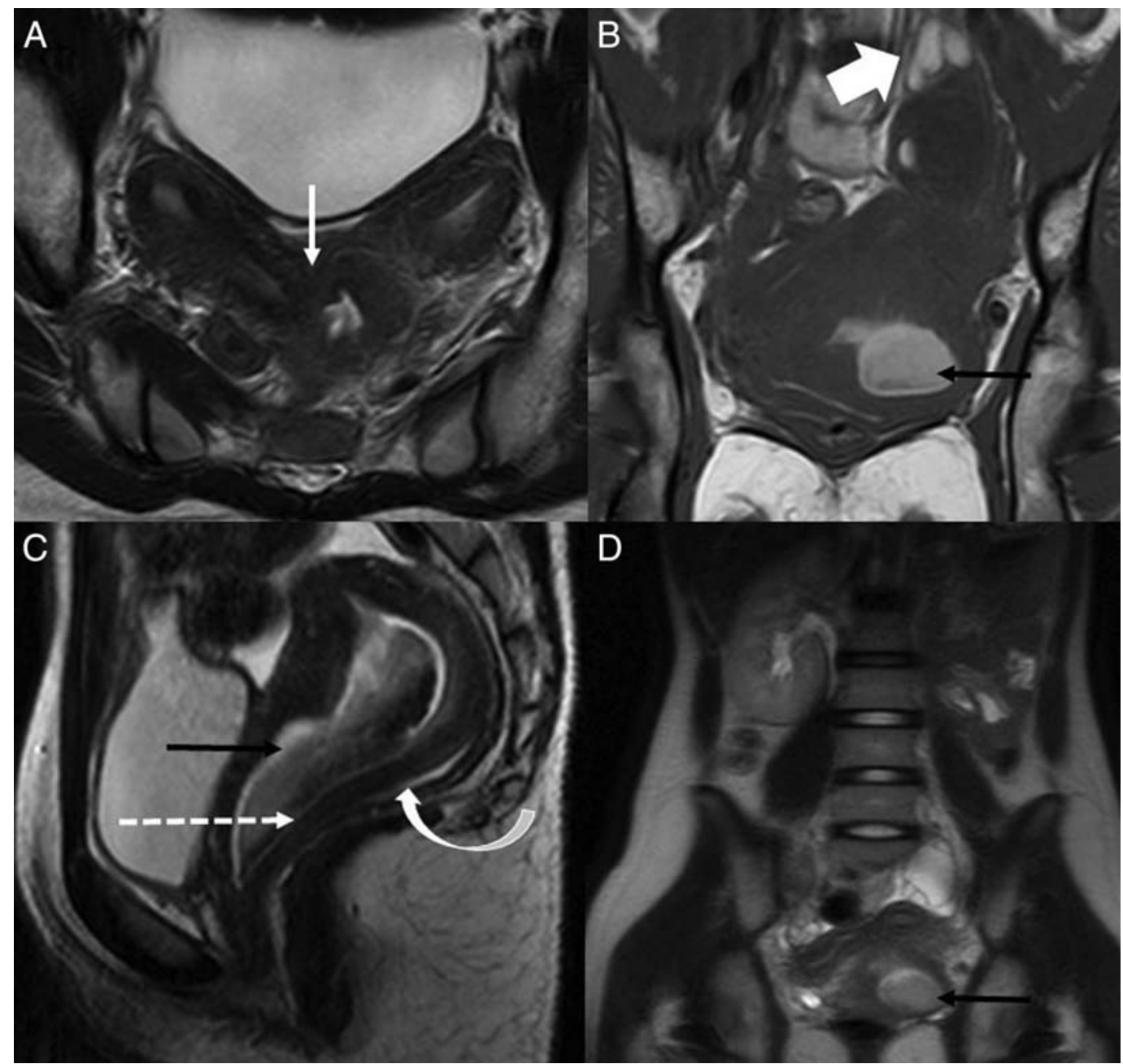

Figure 1 (A) Axial T2-weighted MRI reveal two widely divergent, symmetrical uterine corpii having preserved zonal anatomy, partially fused at the level of cervix (white arrow) without any communication between their endometrial cavities. (B) Coronal T1-weighted and (C) Sagittal T2-weighted MRI shows a thick left hemivaginal septum (dashed arrow) separating the fluid filled dilated left hemivagina, which is hyperintense on T1-weighted and hypointense on T2-weighted images (black arrows), from the normally patent hemivagina of the right system (curved arrow). Note is made of a similar signal intensity tortuous dilated left haemosalpinx (broad white arrow) around the left ovary. (D) Coronal T2-weighted turbo spin echo image shows the true extent of the anomaly demonstrating the uterine didelphys with left haematocolpos (black arrow) and absent left kidney. 
tubular structure was seen extending from left uterine cornu up to the left ovary, findings consistent with haematosalpinx. The right uterine cervix was seen normally opening into the patent right hemivagina (figure 1B, C). In addition, left renal agenesis with compensatory hypertrophy of the right kidney was noted (figure 1D). Bilateral ovaries were normally visualised with a small haemorrhagic cyst seen in the left ovary. A diagnosis of Herlyn-Werner-Wunderlich syndrome (HWWS) was performed and the patient underwent laparoscopic vaginal septectomy, where $500 \mathrm{~mL}$ of chocolate coloured fluid was drained. The patient became symptom free after the procedure.

HWWS is a rare, combined Mullerian and Mesonephric duct anomaly characterised by the triad of uterus didelphys, obstructed hemivagina and ipsilateral renal agenesis. ${ }^{1}$ Uterus didelphys represents failure of fusion of the paired Mullerian ducts. Obstructed hemivagina results from a transverse vaginal septum, which represents vertical fusion defect consequent to non-resorption of tissue between the vaginal plate that originates from the urogenital sinus and the caudal aspect of the paired Mullerian ducts. ${ }^{2}$ The renal agenesis on the same side of the obstructed hemivagina reflects the close embryological association of Wolffian duct in development of Mullerian ducts, whereby developmental anomaly of one Woffian duct may cause unilateral renal agenesis associated with obstructed hemivagina. Unlike our case, which shows a left-sided obstructed system, a prevalence for a right-sided obstructed system has been reported. $^{1}$

The reported incidence of uterine didelphys with renal agensis in the general population is $0.1-3.8 \%$. The most common presenting symptoms of HWWS are cyclical dysmenorrhoea at the onset of puberty, associated with vaginal or pelvic mass. Rarely, it may have delayed presentations of primary infertility, ischiorectal swelling, pyometra or urinary obstruction. ${ }^{12}$

In women, the urethra has a small length, straight course and large diameter and urinary retention is therefore very rare. Fewer than 10 cases of acute urinary retention have been ascribed to haematocolpos. ${ }^{3}$ Acute urinary retention in the setting of haematocolpos can be explained by its mass effect on the urethra causing its stretching or angulation and leading to its obstruction. Another hypothesis is that haematocolpos may cause diminished extruding capacity of the extruder muscle or an increased contractility of the urethral sphincter through the irritation of the sacral plexus base. ${ }^{3}$

MRI is the investigation of choice for suspected Mullerian duct anomalies, as it exquisitely defines the internal and external uterine anatomy, and accurately assesses the complex anomalies, thereby helping diagnose secondary conditions such as fibroids, endometriosis and hydrosalpinx and providing a surgical road map for further management.

The ideal treatment for HWWS is laparoscopic vaginal septum resection and/or septoplasty, but menstrual suppression by oral contraceptive pills or gonadotropin-releasing hormone analogues is advised if immediate surgery is not an option. ${ }^{1}$

Owing to its rarity, HWWS is usually not included in the differentials for acute urinary retention in a young woman, but its early recognition and management can prevent further complications such as endometriosis, pelvic adhesions and infertility. Thus, we would re-emphasise the need for sensitisation of healthcare professionals, especially in emergency units, to this rare entity, HWWS.

\section{Learning points}

- Herlyn-Werner-Wunderlich syndrome (HWWS) is a rare, combined Mullerian and Mesonephric duct anomaly characterised by the triad of uterus didelphys, obstructed hemivagina and ipsilateral renal agenesis.

- A high suspicion index is warranted for early recognition and prompt treatment in order to prevent future serious complications such as endometriosis, pelvic adhesions and infertility.

- In adolescent girls, HWWS can present with acute urinary retention and hence it should be considered as a differential in such a clinical scenario.

Acknowledgements The authors would like to express our gratitude to $\mathrm{Dr}$ Roumina Hasan for her constant support and help in preparing this manuscript. Contributors SK diagnosed the condition and conceptualised the idea of the manuscript and all the authors contributed to design, literature search and final editing of the manuscript.

Competing interests None.

Patient consent Obtained.

Provenance and peer review Not commissioned; externally peer reviewed.

\section{REFERENCES}

1 Del Vescovo R, Battisti S, Di Paola V, et al. Herlyn-Werner-Wunderlich syndrome: MRI findings, radiological guide (two cases and literature review), and differential diagnosis. BMC Med Imaging 2012;12:4.

2 Arıkan II, Harma M, Harma Mi, et al. Herlyn-Werner-Wunderlich syndrome (uterus didelphys, blind hemivagina and ipsilateral renal agenesis) - a case report. J Turk Ger Gynecol Assoc 2010;11:107-9.

3 Patoulias I, Prodromou K, Kallergis K, et al. Acute urinary retention due to hematocolpos: report of two cases. J Pediat Surg Case Rep 2013;1:189-91.

Copyright 2015 BMJ Publishing Group. All rights reserved. For permission to reuse any of this content visit

http://group.bmj.com/group/rights-licensing/permissions.

BMJ Case Report Fellows may re-use this article for personal use and teaching without any further permission.

Become a Fellow of BMJ Case Reports today and you can:

- Submit as many cases as you like

- Enjoy fast sympathetic peer review and rapid publication of accepted articles

- Access all the published articles

- Re-use any of the published material for personal use and teaching without further permission

For information on Institutional Fellowships contact consortiasales@bmjgroup.com

Visit casereports.bmj.com for more articles like this and to become a Fellow 